\title{
Flu-IV score: a predictive tool for assessing the risk of invasive mechanical ventilation in patients with influenza-related pneumonia
}

Liang Chen ${ }^{1,2^{*}}$, Xiudi Han ${ }^{3}$, YanLi Li ${ }^{4}$, Chunxiao Zhang ${ }^{5}$ and Xiqian Xing ${ }^{6}$

\begin{abstract}
Background: The need for invasive mechanical ventilation (IMV) is linked to significant morbidity and mortality in patients with influenza-related pneumonia (Flu-p). We aimed to develop an assessment tool to predict IMV among Flu-p patients within 14 days of admission.
\end{abstract}

Methods: In total, 1107 Flu-p patients from five teaching hospitals were retrospectively enrolled from January 2012 to December 2019, including 895 patients in the derivation cohort and 212 patients in the validation cohort. The predictive model was established based on independent risk factors for IMV in the Flu-p patients from the derivation cohort.

Results: Overall, 10.6\% (117/1107) of patients underwent IMV within 14 days of admission. Multivariate regression analyses revealed that the following factors were associated with IMV: early neuraminidase inhibitor use $(-3$ points), lymphocytes $<0.8 \times 10^{9} / \mathrm{L}$ (1 point), multi-lobar infiltrates (1 point), systemic corticosteroid use (1 point), age $\geq 65$ years old (1 points), $\mathrm{PaO}_{2} / \mathrm{FiO}_{2}<300 \mathrm{mmHg}$ ( 2 points), respiratory rate $\geq 30$ breaths $/ \mathrm{min}$ (3 points), and arterial $\mathrm{PH}<7.35$ (4 points). A total score of five points was used to identify patients at risk of IMV. This model had a sensitivity of $85.5 \%$, a specificity of $88.8 \%$, and exhibited better predictive performance than the ROX index (AUROC $=0.909$ vs. $0.594, p=0.004$ ), modified ROX index (AUROC $=0.909$ vs. $0.633, p=0.012$ ), and HACOR scale (AUROC $=0.909$ vs. $0.622, p<0.001)$ using the validation cohort.

Conclusions: Flu-IV score is a valuable prediction rule for 14-day IMV rates in Flu-p patients. However, it should be validated in a prospective study before implementation.

Keywords: Influenza, Pneumonia, Invasive mechanical ventilation, Prediction rule

\section{Background}

Influenza is a common viral respiratory disease that affects between 5 and $10 \%$ of the population of the world each year, resulting in 3-5 million severe infections and between 290,000 and 650,000 annual deaths attributable to influenza-related illness [1]. Owing to the significant morbidity and mortality associated with disease,

\footnotetext{
*Correspondence: chenliang1995@sina.com

${ }^{1}$ Department of Infectious Diseases, Nanjing Lishui People's Hospital, No.

86 Chongwen Road, Lishui District, Nanjing, China

Full list of author information is available at the end of the article
}

influenza is considered by many researchers to be one of the greatest threats to global public health [2]. So, even during the pandemic of COVID-19, the prevention and treatment of influenza should not be ignored.

Influenza-related pneumonia (Flu-p) is a severe form of influenza infection associated with over $50 \%$ of influenzarelated hospitalization and mortality [3]. Flu-p can progress from relatively mild disease to more severe cases that can cause ARDS or respiratory failure such that patients must often undergo invasive mechanical ventilation (IMV) within 3-10 days following initial symptom

(c) The Author(s) 2022. Open Access This article is licensed under a Creative Commons Attribution 4.0 International License, which permits use, sharing, adaptation, distribution and reproduction in any medium or format, as long as you give appropriate credit to the original author(s) and the source, provide a link to the Creative Commons licence, and indicate if changes were made. The images or other third party material in this article are included in the article's Creative Commons licence, unless indicated otherwise in a credit line to the material. If material is not included in the article's Creative Commons licence and your intended use is not permitted by statutory regulation or exceeds the permitted use, you will need to obtain permission directly from the copyright holder. To view a copy of this licence, visit http://creativecommons.org/licenses/by/4.0/. The Creative Commons Public Domain Dedication waiver (http://creativeco mmons.org/publicdomain/zero/1.0/) applies to the data made available in this article, unless otherwise stated in a credit line to the data. 
onset $[4,5]$. The need for IMV is linked to higher rates of patient morbidity and mortality [6], and evaluating a given patient's odds of requiring IMV is thus a valuable prognostic approach. However, the risk factors associated with the need for IMV have not been fully clarified. Certain assessment tools have been established in an effort to gauge the odds of IMV in individuals suffering from acute hypoxemic respiratory failure, including the ROX index (pulse oximetry $/ \mathrm{FiO}_{2}$ to respiratory rate) [7], modified ROX index $\left(\mathrm{PaO}_{2} / \mathrm{FiO}_{2}\right.$ to respiratory rate) [8], and $\mathrm{HACOR}$ scale (heart rate, respiratory rate, arterial $\mathrm{pH}$, $\mathrm{PaO}_{2} / \mathrm{FiO}_{2}$ and Glasgow Coma Scale) [9]. These tools, however, are not specific to Flu-p patients, nor have any studies specifically examined their predictive power in individuals suffering from Flu-p, and there is thus a clear need for the development of a reliable tool that can predict the requirement for IMV in Flu-p patients at an early time point prior to the onset of potential respiratory failure.

As such, we performed the present retrospective multicenter study with the goal of developing an accurate and easy-to-use assessment tool capable of predicting the odds of a given Flu-p patient undergoing IMV within 14 days of admission.

\section{Methods}

\section{Patient recruitment}

For this study, patients for whom influenza virus nucleic acid testing was performed in the microbiology labs of five tertiary hospitals in China (Additional file 1: Supplementary Material 1) from January 1st, 2012 to December 31st, 2019 were screened for eligibility. Those patients with confirmed Flu-p were enrolled in this study. Patients were excluded if they: (1) were not classified as having community-onset pneumonia (with pneumonia onset $\geq 48 \mathrm{~h}$ after admission [10]), as the inclusion of nosocomial pneumonia cases had the potential to complicate result interpretations; (2) were $<18$ years old; (3) were immunocompromised, given that the clinical features and outcomes of immunocompromised patients were different from those of immunocompetent hosts [11]; or (4 had been intubated prior to admission.

\section{Study definitions}

Patients with Flu-p were defined as individuals for whom polymerase chain reaction (PCR) analyses of respiratory specimens (including sputum, nasal/nasopharyngeal swabs, bronchial aspirates, and bronchoalveolar lavage fluid) were positive for influenza viral RNA, and for whom respiratory symptoms and chest radiographic findings were consistent with newly emergent chest infiltrates. The decisions to initiate IMV were taken by the attending physicians, based on the presence of any of the following intubation criteria: respiratory or cardiac arrest, respiratory pauses with loss of alertness or gasping for air, severely impaired consciousness, major agitation inadequately controlled by sedation, signs of exhaustion, massive aspiration, inability to manage respiratory secretions appropriately, and hemodynamic instability without response to fluids and vasoactive agents. Additionally, patients were also intubated in case of subsequent worsening of gas exchange or respiratory distress despite supportive measures [12]. Early neuraminidase inhibitor (NAI) therapy was defined as the administration of NAI agents within two days of symptom onset [13]. Systemic corticosteroid treatment was defined by the administration of one or more systemic corticosteroid doses at admission. Community-acquired co-infecting respiratory pathogens were defined as pathogens detected via standard microbiological techniques (Additional file 1: Supplementary Material 2) within $48 \mathrm{~h}$ following admission [14].

\section{Data collection}

Data extracted from patient medical records with a standard case report form included demographic details, patient comorbidities (see Additional file 1: Supplementary Material 3), patient symptoms, vital signs, laboratory results, radiographic findings before invasive ventilation at the day of admission (if there were multiple results, the worst value was extracted), community-acquired coinfecting respiratory pathogens, patient management, and outcome data (including NAI use, systemic corticosteroid administration, IMV, and 14-day mortality). Outcomes for those hospitalized for $<14$ days were established through follow-up via telephone.

\section{Statistical analysis}

In total, 1107 Flu-p patients were identified and enrolled in this study. These patients were then randomly assigned to derivation and validation cohorts $(80 \%$ and $20 \%$ of patients, respectively), which were respectively used to develop and validate our prognostic model.

In addition, the patients in the derivation cohort were separated into two groups based upon whether or not they underwent IMV within 14 days following admission. Baseline characteristics were then compared between these two patient groups, and all variables which yielded a $p<0.1$ in these initial univariable analyses were incorporated into a multivariable backward stepwise logistic regression model to identify risk factors associated with 14-day IMV rates. To ensure model simplicity, each risk factor was assigned an integer score value associated with its corresponding regression coefficient $(\beta)$ value. Model cutoff scores were then defined using receiver operating characteristic (ROC) curves based upon Youden's index. 
Kaplan-Meier analyses were conducted to compare rates of IMV between patients above and below this cutoff score (high-risk and low-risk, respectively). The area under the ROC curve (AUROC) was used to gauge the prognostic performance of this model based upon overall sensitivity and specificity values. Model calibration was assessed by comparing the predicted risk of IMV with the observed risks, and examined using the Hosmer-Lemeshow goodness-of-fit statistic.

To handle the missing data, multiple imputation was first performed by chained equations, which use linear regression to impute continuous variables and (multinomial) logistic regression to impute categorical/binary variables [15]. The interaction of independent variables was checked by a multicollinearity test using the variance inflation factor (VIF), and no problem was detected $(0<\mathrm{VIF}<10)$.

A Kolmogorov-Smirnov test was used to assess result normality, with normally and non-normally distributed variables being presented as means \pm standard deviation and medians, respectively. Continuous variables were evaluated with Mann-Whitney $U$ tests or Student's t-tests, whereas categorical variables were assessed with Fisher's exact test or chi-squared tests. A two-tailed $p<0.05$ was indicative of significance. SPSS 22.0 or MedCalc 19.0 were used for all statistical testing.

\section{Results}

\section{Patient screening}

A total of 3405 hospitalized patients who were found to be positive for influenza viral RNA during the study period were screened for eligibility, of whom 1107 with laboratory-confirmed Flu-p were enrolled in this study (Fig. 1).

\section{Patient characteristics}

Enrolled patients exhibited a median age of 61.0 years, and were $54.5 \%(603 / 1107)$ male. The most prevalent comorbidities in these patients included cardiovascular disease $(22.7 \%, 251 / 1107)$, diabetes mellitus $(13.4 \%$,

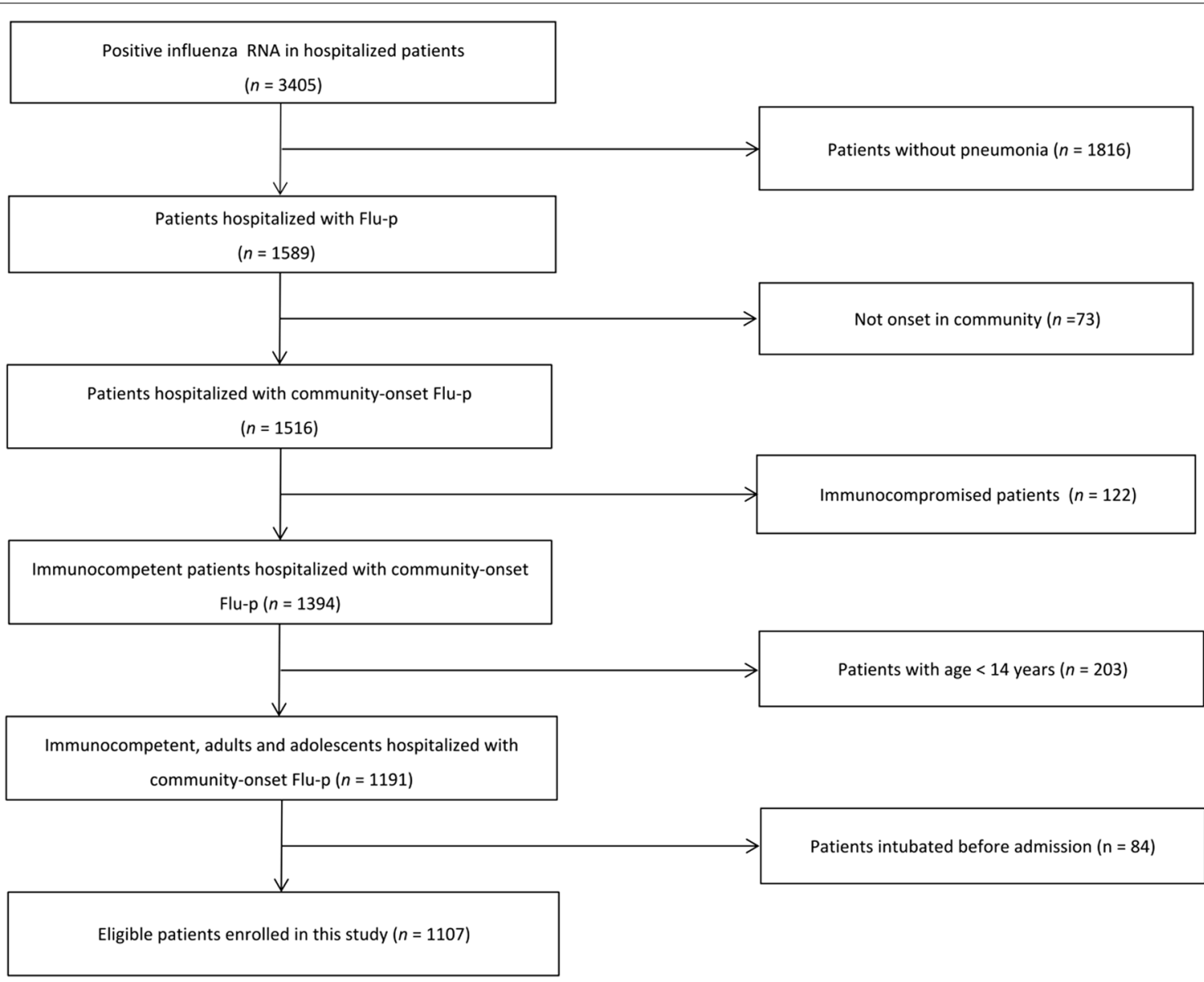

Fig. 1 Patient screening algorithm for Flu-p. A total of 3405 patients were screened, and 1107 patients with laboratory-confirmed Flu-p were enrolled in this study 
148/1107), and cerebrovascular disease $(10.3 \%, 114 / 1107)$ (Additional file 1: Supplementary material 4). In total, $33.5 \%(371 / 1107)$ patients were found to be co-infected with other community-acquired pathogens (Additional file 1: Supplementary Material 5). Of these patients, noninvasive mechanical ventilation (NIMV) and IMV were respectively conducted within 14 days of admission for $11.6 \%(128 / 1107)$ and $10.6 \%(117 / 1107)$ of patients. The all-cause 14-day mortality rate for these patients was $3.2 \%(35 / 1107)$ (Additional file 1: Supplementary material $4)$.

\section{Risk factors associated with 14-day IMV rates in Flu-p patients}

Next, univariable analyses were conducted in the derivation cohort, which identified age $\geq 65$ years old, influenza A virus infection, the presence of solid malignant tumors, a respiratory rate $\geq 30$ breaths/min, a leukocyte count $>10 \times 10^{9} / \mathrm{L}, \quad$ Lymphocytes $<0.8 \times 10^{9} / \mathrm{L}, \quad$ albumin $<35 \mathrm{~g} / \mathrm{L}$, arterial $\mathrm{PH}<7.35, \mathrm{PaO}_{2} / \mathrm{FiO}_{2}<300 \mathrm{mmHg}$, early NAI therapy, and systemic corticosteroids use at admission associated with 14-day IMV rates in Flu-p patients (Table 1).

In a subsequent multivariable logistic regression model, factors that were identified as independent predictors of a higher risk of requiring IMV in Flu-p patients (Fig. 2) included: early NAI use (OR 0.014, 95\% CI 0.003$0.083, p<0.001 ;-3$ points), multilobar infiltrates $(O R$ 4.568, 95\% CI 1.591-13.118, $p=0.007$; 1 point), lymphocytes $<0.8 \times 10^{9} / \mathrm{L}($ OR $5.755,95 \%$ CI $2.261-14.649$, $p<0.001$; 1 point), systemic corticosteroid administration (OR 5.874, 95\% CI 2.356-14.642, $p<0.001$; 1 points), age $\geq 65$ years old (OR 9.052, 95\% CI 3.544-23.119, $p<0.001 ; 1$ points), $\mathrm{PaO}_{2} / \mathrm{FiO}_{2}<300 \mathrm{mmHg}$ (OR 9.966, 95\% CI 3.619-27.447, $p<0.001 ; 2$ points), respiratory rate $\geq 30$ breaths/min (OR 53.835, 95\% CI 19.711147.033, $p<0.001 ; 3$ points), and arterial $\mathrm{PH}<7.35$ (OR 255.404, 95\% CI 42.701-527.608, $p<0.001$; 4 points).

\section{Assessment of the predictive performance of Flu-IV scores}

The AUROC value for the Flu-IV score model developed based upon the above multivariable analysis was 0.909 in our validation patient cohort (95\% CI 0.851-0.950), and was higher than that of the ROX index (AUROC $=0.594$, 95\% CI $0.510-0.674, p=0.004)$, modified ROX index (AUROC $=0.633,95 \% C I 0.550-0.710, p=0.012$ ), or HACOR scale (AUROC $=0.622,95 \%$ CI $0.539-0.700$, $p<0.001$ ) (Additional file 1: Supplementary Material 6 and Fig. 3). Similar findings were also independently made in the derivation cohort (Additional file 1: Supplementary Material 7 and Supplementary Fig. 1).

A good performance was observed between the observed and predicted risk of IMV from the derivation cohort and validation cohort, indicating that the algorithms were well calibrated (Additional file 1: Supplementary Fig. 2).

Table 2 compiles the mortality rates, sensitivity, and specificity values associated with our Flu-IV score model in the overall patient cohort. Patients were stratified into high- and low-risk cohorts based upon whether they had Flu-IV scores that were above or below the optimal cutoff score of 5 points. Subsequent Kaplan-Meier curves confirmed that high-risk patients were significantly more likely to require IMV relative to low-risk patients $(47.4 \%$ vs. $1.9 \%$, log-rank test, $p<0.001$ ) (Fig. 4).

\section{Discussion}

This was a multicenter retrospective study designed to develop a novel model capable of predicting the odds of IMV within 14 days of admission for Flu-p patients. Our resultant Flu-IV risk score model can be used to reliably predict 14-day IMV rates in Flu-p patients.

We found that $10.6 \%$ of the patients in the present study necessitated IMV within 14 days of admission, in line with prior reports regarding severe influenza patient outcomes $[16,17]$. The 14-day mortality of patients that did require IMV was significantly greater than that of patients that did not. As $92.1 \%$ of Flu-p patients that undergo IMV do so within 14 days of admission, predicting 14-day IMV rates is critical to appropriate patient management.

We identified multiple variables that are known to be associated with more severe influenza and that were also associated with a higher risk of IMV in Flu-p patients [18], including age $>65$ years, a lymphocyte count $<0.8 \times 10^{9} / \mathrm{L}$, and systemic corticosteroid use. Cellular immunity is a key mediator of antiviral responses [19], and advanced age is associated with a decline in overall patient immune status [20]. Severe influenza is also often characterized by lymphocytopenia in $50-100 \%$ of cases [21,22], although the mechanistic basis for this finding remains poorly understood. There is some evidence that $\mathrm{CD} 4+$ and $\mathrm{CD} 8+\mathrm{T}$ cells may undergo higher rates of apoptotic death in individuals with severe disease owing to higher circulating levels of soluble Fas ligand and caspase-1 [23], thereby contributing to an overall decline in lymphocyte counts. Such virus-induced lymphocytopenia can delay viral clearance. Alternatively, these lymphocytes may be recruited to the respiratory tract and other organs, resulting in their apparent depletion from circulation [24]. Lymphocyte accumulation within the lungs can drive more severe localized inflammation and tissue damage. Systemic corticosteroid use can suppress overall immune functionality and increase the odds of developing severe nosocomial pneumonia necessitating IMV $[25,26]$. 
Table 1 Comparison of clinical characteristics and outcomes between patients needing and weaning from IMV from derivation cohort

\begin{tabular}{|c|c|c|c|}
\hline Variable & $\begin{array}{l}\text { Needing IMV } \\
(n=99)\end{array}$ & $\begin{array}{l}\text { Weaning from IMV } \\
(n=796)\end{array}$ & $p$ Value \\
\hline Age $\geq 65$ years old $(n, \%){ }^{\#}$ & $66(66.7)$ & $334(42.0)$ & $<0.001$ \\
\hline Male $(n, \%)$ & $55(55.6)$ & $421(52.9)$ & 0.616 \\
\hline Influenza A infection $(n, \%) \#$ & $72(72.7)$ & $471(59.2)$ & 0.009 \\
\hline \multicolumn{4}{|l|}{ Comorbidities ( $n, \%)$} \\
\hline Cardiovascular disease & $26(26.3)$ & $176(22.1)$ & 0.351 \\
\hline Diabetes mellitus & $11(11.1)$ & $102(12.8)$ & 0.630 \\
\hline Cerebrovascular disease & $9(9.1)$ & $78(9.8)$ & 0.823 \\
\hline COPD & $10(10.1)$ & $75(9.4)$ & 0.828 \\
\hline Chronic kidney disease & $0(0.0)$ & $29(3.6)$ & 0.103 \\
\hline Asthma & $1(1.0)$ & $23(2.9)$ & 0.446 \\
\hline Solid Malignant tumor \# & $8(8.1)$ & $13(1.6)$ & $<0.001$ \\
\hline Pregnancy $(n, \%)$ & $0(0.0)$ & $6(0.8)$ & 1.000 \\
\hline Obesity $(n, \%)$ & $4(4.0)$ & $53(6.7)$ & 0.314 \\
\hline Smoking history $(n, \%)$ & $24(24.2)$ & $215(27.0)$ & 0.557 \\
\hline \multicolumn{4}{|l|}{ Baseline clinical and radiologic features $(n, \%)$} \\
\hline Mental confusion & $15(15.2)$ & $96(12.1)$ & 0.379 \\
\hline Respiratory rates $\geq 30$ breaths/min $\#$ & $54(54.5)$ & $77(9.7)$ & $<0.001$ \\
\hline $\mathrm{SBP}<90 \mathrm{mmHg}$ & $1(1.0)$ & $6(0.8)$ & 0.561 \\
\hline Leukocytes $>10 \times 10^{9} / \mathrm{L}^{\#}$ & $14(14.1)$ & $203(25.5)$ & 0.013 \\
\hline Lymphocytes $<0.8 \times 10^{9} / \mathrm{L}^{\#}$ & $67(67.7)$ & $312(39.2)$ & $<0.001$ \\
\hline $\mathrm{HB}<100 \mathrm{~g} / \mathrm{L}$ & $18(18.2)$ & $179(22.5)$ & 0.329 \\
\hline $\mathrm{ALB}<35 \mathrm{~g} / \mathrm{L}^{\#}$ & $10(10.1)$ & $153(19.2)$ & 0.014 \\
\hline $\mathrm{BUN}>7 \mathrm{mmol} / \mathrm{L}$ & $35(35.4)$ & $316(39.7)$ & 0.386 \\
\hline $\mathrm{BG}>14 \mathrm{mmol} / \mathrm{L}$ & $0(0.0)$ & $8(1.0)$ & 0.606 \\
\hline Arterial $\mathrm{PH}<7.35^{\#}$ & $21(22.2)$ & $67(8.4)$ & 0.001 \\
\hline $\mathrm{PaO}_{2} / \mathrm{FiO}_{2}<300 \mathrm{mmHg}$ \# & $81(81.8)$ & $351(44.1)$ & $<0.001$ \\
\hline $\mathrm{PaCO}_{2}>50 \mathrm{mmHg}$ & $7(7.1)$ & $82(10.3)$ & 0.133 \\
\hline Multilobar infiltrates $\#$ & $77(77.8)$ & $558(70.1)$ & 0.113 \\
\hline Pleural effusion & $27(27.3)$ & $251(31.5)$ & 0.388 \\
\hline Coinfections $(n, \%)$ & $32(32.3)$ & $270(33.9)$ & 0.751 \\
\hline Early NAI therapy $(n, \%)^{\#}$ & $17(17.2)$ & $294(36.9)$ & $<0.001$ \\
\hline Systemic corticosteroids use at admission $(n, \%){ }^{\#}$ & $21(21.2)$ & $32(4.0)$ & $<0.001$ \\
\hline Noninvasive ventilation within 14 days after admission $(n, \%)$ & $17(17.2)$ & $94(11.8)$ & 0.127 \\
\hline
\end{tabular}

$I M V$ invasive mechanical ventilation, NIMV noninvasive mechanical ventilation, $C O P D$ chronic obstructive pulmonary disease, $S B P$ systolic blood pressure, $H B$ hemoglobin, $A L B$ albumin, $B U N$ blood urea nitrogen, $\mathrm{BG}$ blood glucose, $\mathrm{PaO}_{2} / \mathrm{FiO}_{2}$ arterial pressure of oxygen/fraction of inspiration oxygen, $\mathrm{NAI}$ neuraminidase inhibitor. \#: variables cited in the table above were the candidates which were entered into the multivariate logistic regression model. The bolded values are $p$ values $<0.05$, which represented significant differences between patients needing and free of invasive ventilation

Severe Flu-p is characterized by impaired pulmonary function and diffuse alveolar damage [27], with tachypnea and decreased $\mathrm{PaO}_{2} / \mathrm{FiO}_{2}$ serving as direct manifestations of such pulmonary damage. Pneumonia patients also often exhibit metabolic acidosis that is linked to hyper-inflammation and impaired tissue perfusion [28], thereby exacerbating pulmonary damage. Impaired pulmonary function and the retention of carbon dioxide in the lungs can further drive respiratory acidosis, leading to higher rates of NIMV failure and an increased risk of requiring IMV [29]. Many observational studies showed inhibiting viral replication at early time points can reduce virus-induced inflammation and tissue damage, thereby decreasing overall influenza-related mortality rates [3032]. Our data also suggest that early NAI treatment was associated with a lower risk of Flu-p patient intubation.

The ROX/modified ROX index are designed to predict failure of high flow oxygen by nasal cannula at 2, 6 and $12 \mathrm{~h}$ after start. The HACOR scale predicts noninvasive ventilation (NIV) failure within $1 \mathrm{~h}$ after the 


\begin{tabular}{|c|c|c|c|c|c|c|}
\hline & & & OR $(95 \% \mathrm{Cl})$ & $P$ value & $\beta$ & Score \\
\hline Early NAI therapy & $\rightarrow$ & & $0.014(0.003-0.083)$ & $<0.001$ & -4.234 & -3 \\
\hline Multilobar infiltrates & & $\rightarrow$ & $4.568(1.591-13.118)$ & 0.007 & 1.519 & 1 \\
\hline Lymphocytes $<0.8 \times 10^{9} / \mathrm{L}$ & & $\rightarrow$ & $5.755(2.261-14.649)$ & $<0.001$ & 1.750 & 1 \\
\hline Systemic corticosteroids use & & $\rightarrow$ & $5.874(2.356-14.642)$ & $<0.001$ & 1.770 & 1 \\
\hline Age $\geqslant 65$ years old & & $\rightarrow$ & $9.052(3.544-23.119)$ & $<0.001$ & 2.203 & 1 \\
\hline $\mathrm{PaO}_{2} / \mathrm{FiO}_{2}<300 \mathrm{mmHg}$ & & $\rightarrow$ & $9.966(3.619-27.447)$ & $<0.001$ & 2.299 & 2 \\
\hline Respiratory rates $\geqslant 30$ breaths $/ \mathrm{min}$ & & $\rightarrow$ & 53.835 (19.711-147.033) & $<0.001$ & 3.986 & 3 \\
\hline Arterial $\mathrm{PH}<7.35$ & & $\longrightarrow$ & $255.404(42.701-527.608)$ & $<0.001$ & 5.543 & 4 \\
\hline
\end{tabular}

Fig. 2 Risk factors associated with invasive mechanical ventilation in Flu-p patients. A multivariate logistic regression model identified the following factors as independent predictors of a higher risk of requiring IMV in Flu-p patients: early NAl use, lymphocytes $<0.8 \times 10^{9} / \mathrm{L}$, multilobar infiltrates, age $\geq 65$ years old, systemic corticosteroid administration, $\mathrm{PaO}_{2} / \mathrm{FiO}_{2}<300 \mathrm{mmHg}$, respiratory rate $\geq 30$ breaths/min, and arterial $\mathrm{PH}<7.35$

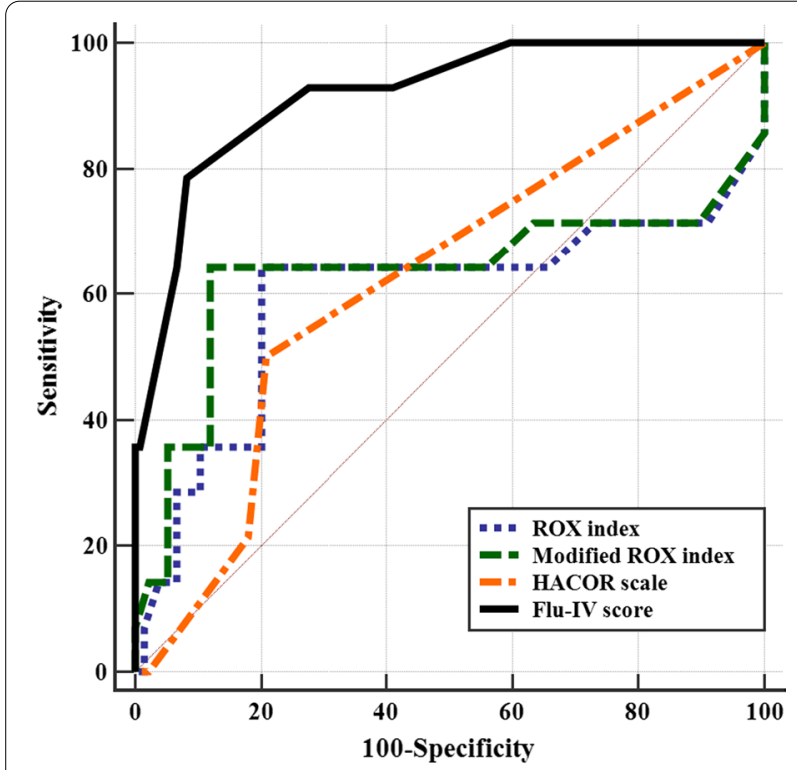

Fig. 3 ROCs for IMV prediction of four scorings in Flu-p patients from validation cohort. The AUROC value for the Flu-IV score model was 0.909, which was higher than that of the ROX index $(A \cup R O C=0.594)$, modified ROX index $(A U R O C=0.633)$ and $\mathrm{HACOR}$ scale $(A \cup R O C=0.622)$

start of NIV. The time window and intended use of these scores differ to our Flu-IV substantially. In addition, the ROX/modified ROX and the HACOR scale are only applied to the patients suffering from hypoxemia. However, just $49 \%$ of patients in the present study cohort exhibited hypoxemia upon admission. Importantly, these scoring systems were not designed for the analysis of Flu-p patients. While some of the variables included in our Flu-IV model were the same as those included in the ROX, modified ROX, and HACOR scales, these tools were not able to reliably predict IMV rates among Flu-p patients at the day of admission. A Flu-IV cutoff score of 5 was able to effectively stratify Flu-p patients into low- and high-risk categories. Considering its good negative prediction value, the Flu-IV score could be used particularly as a rule-out approach to early discharge patient with a low score. Importantly, our Flu-IV scoring model is simple, allowing clinicians to predict the odds of a given patient requiring IMV within 14 days of admission based upon eight parameters that can be readily measured even in small or primary hospitals. This model can be used to evaluate patients at an early time point prior to the onset of respiratory failure, and as such, we believe it represents a valuable tool for the management of Flu-p patients.

There are certain limitations to this analysis. For one, as this study was retrospective in design, it is susceptible to selection bias. Nucleic acid tests, for example, we conducted based upon the subjective judgment of the attending physicians such that only patients with more severe disease may have undergone such testing, rather than all potentially eligible patients. Furthermore, it was possible that a very few patients required IMV did not consent to intubation. As this study was retrospective, we were also unable to retrieve and evaluate patient vaccination data or other missing information, potentially constraining the accuracy of our findings. Patients were also not routinely evaluated for other respiratory viruses, and we are thus unable to exclude the possibility that certain patients may have been coinfected with multiple viruses. 
Table 2 Flu-IV score and actual proportion of patients needing IMV

\begin{tabular}{|c|c|c|c|c|c|c|c|}
\hline Score & $\begin{array}{l}\text { Cases of IMV } \\
(n, \%)\end{array}$ & $\begin{array}{l}\text { Sensitivity } \\
\text { (\%) }\end{array}$ & $95 \% \mathrm{Cl}$ & $\begin{array}{l}\text { Specificity } \\
(\%)\end{array}$ & $95 \% \mathrm{Cl}$ & $+\mathrm{LR}$ & $-\mathrm{LR}$ \\
\hline-3 & $0 / 11(0.0)$ & 100.00 & $96.9-100.0$ & 0.00 & $0.0-0.5$ & 1.00 & \\
\hline-2 & $0 / 58(0.0)$ & 100.00 & $96.9-100.0$ & 1.11 & $0.6-2.0$ & 1.01 & 0.00 \\
\hline-1 & 1/64 (1.6) & 100.00 & $96.9-100.0$ & 6.97 & $5.5-8.7$ & 1.07 & 0.00 \\
\hline 0 & 1/98 (1.0) & 99.15 & $95.3-100.0$ & 13.33 & $11.3-15.6$ & 1.14 & 0.064 \\
\hline 1 & $1 / 149(0.7)$ & 98.29 & $94.0-99.8$ & 23.13 & $20.5-25.9$ & 1.28 & 0.074 \\
\hline 2 & $1 / 124(0.8)$ & 97.44 & $92.7-99.5$ & 38.08 & $35.0-41.2$ & 1.57 & 0.067 \\
\hline 3 & 9/235 (3.8) & 96.58 & $91.5-99.1$ & 50.51 & $47.3-53.7$ & 1.95 & 0.068 \\
\hline 4 & 4/157 (2.5) & 88.89 & 81.7-93.9 & 73.33 & $70.5-76.1$ & 3.33 & 0.15 \\
\hline 5 & 27/82 (32.9) & 85.47 & 77.8-91.3 & 88.79 & 86.7-90.7 & 7.62 & 0.16 \\
\hline 6 & 23/71 (32.4) & 62.39 & $53.0-71.2$ & 94.34 & $92.7-95.7$ & 11.03 & 0.40 \\
\hline 7 & 15/23 (65.2) & 42.74 & $33.6-52.2$ & 99.19 & $98.4-99.7$ & 52.88 & 0.58 \\
\hline 8 & $35 / 35(100.0)$ & 29.91 & 21.8-39.1 & 100.00 & $99.6-100.0$ & & 0.70 \\
\hline 9 & - & 0.00 & $0.0-3.1$ & 100.00 & $99.6-100.0$ & & 1.00 \\
\hline
\end{tabular}

$C l$ confidence interval, $+L R$ positive likelihood ratio, $-L R$ negative likelihood ratio

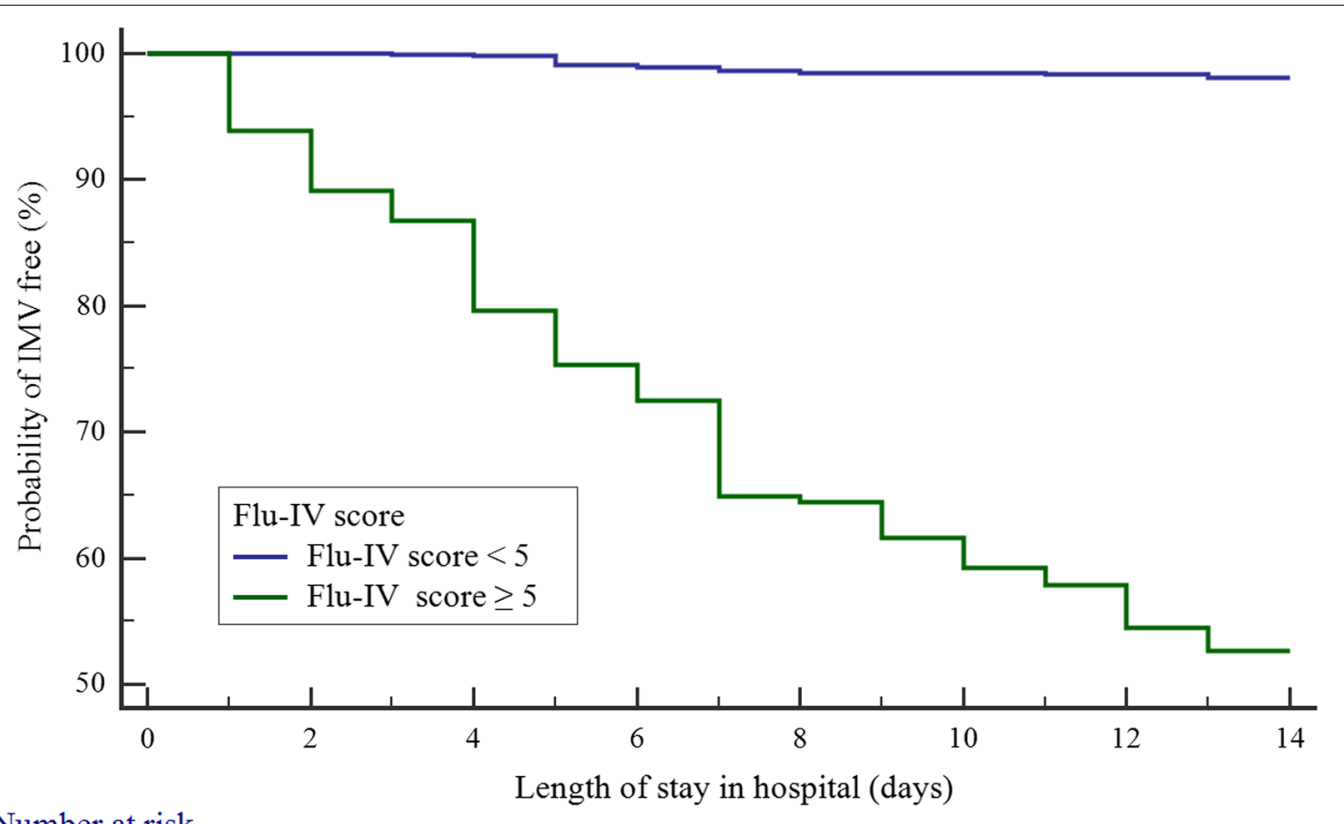

Number at risk

Group: Flu-IV score $<5$

$$
896 \quad 896
$$

Group: Flu-IV score $\geq 5$

$$
211 \quad 188
$$

\section{Conclusions}

In summary, we developed a reliable and straightforward predictive tool capable of gauging the odds of a given hospitalized Flu-p patient requiring IMV. This tool will help clinicians better evaluate the risks of early intubation for any given patient such that they can make optimal clinical judgments. However, it should be evaluated in more large-sample and prospective studies. 


\section{Abbreviations}

IMV: Invasive mechanical ventilation; Flu-p: Influenza-related pneumonia; $\mathrm{ROX}$ index: Pulse oximetry/ $\mathrm{FiO}_{2}$ to respiratory rate; modified $\mathrm{ROX}$ index: $\mathrm{PaO}_{2} /$ $\mathrm{FiO}_{2}$ to respiratory rate; $\mathrm{HACOR}$ scale: Heart rate, respiratory rate, arterial $\mathrm{pH}$, $\mathrm{PaO}_{2} / \mathrm{FiO}_{2}$ and Glasgow Coma Scale; PCR: Polymerase chain reaction; NAI: Neuraminidase inhibitor; OR: Odds ratio; 95\% IC: 95\% Interval confidence; IQR: Interquartile range; ROC: Receiver operating characteristic; AUROC: Area under the ROC curve; COPD: Chronic obstructive pulmonary disease; SBP: Systolic blood pressure; Hb: Hemoglobin; ALB: Albumin; BUN: Blood urea nitrogen; $\mathrm{PH}$ Hydrogen ion index; $\mathrm{pO}_{2} / \mathrm{FiO}_{2}$ : Arterial pressure of oxygen/fraction of inspiration oxygen.

\section{Supplementary Information}

The online version contains supplementary material available at https://doi. org/10.1186/s12890-022-01833-2.

Additional file 1. Detailed and additional data of this manuscript.

\section{Acknowledgements}

The authors would like to express their gratitude to BMCSCl (http://www. bmcscience.com/) for the expert linguistic services provided.

\section{Authors' contributions}

Study concept and design: LC, XdH. Acquisition of data: LC, XdH, YIL, CXZ, XqX. Statistical analysis of data: LC. Drafting of the manuscript: LC. Critical revision of the manuscript for important intellectual content: $\mathrm{XdH}, \mathrm{XqX}$. All authors agree with the article submission. All authors read and approved the final manuscript.

\section{Funding}

This study is founded by Beijing JST research (ZR-201921).

\section{Availability of data and materials}

All data generated or analysed during this study are included in this published article and its Additional file 1.

\section{Declarations}

\section{Ethics approval and consent to participate}

The study design was approved by the Ethics Committee of Beijing Jishuitan Hospital (No.201911-15). Given the retrospective nature of the study, the informed consent was waived by the Ethics Committee of Beijing Jishuitan Hospital.

\section{Consent for publication}

Not applicable.

\section{Competing interests}

The authors declare that they have no competing interests.

\section{Author details}

'Department of Infectious Diseases, Nanjing Lishui People's Hospital, No. 86 Chongwen Road, Lishui District, Nanjing, China. ${ }^{2}$ Department of Infectious Diseases, Beijing Jishuitan Hospital, 4th Medical College of Peking University, Beijing, China. ${ }^{3}$ Department of Pulmonary and Critical Care Medicine, Qingdao Municipal Hospital, Qingdao City, Shandong Province, China. ${ }^{4}$ Department of Infectious Diseases and Clinical Microbiology, Beijing Chao-Yang Hospital, Capital Medical University, Beijing, China. ${ }^{5}$ Department of Pulmonary and Critical Care Medicine, Beijing Huimin Hospital, Beijing, China. ${ }^{6}$ Department of Pulmonary and Critical Care Medicine, The 2nd People's Hospital of Yunnan Province, Kunming City, Yunnan Province, China.

Received: 21 April 2021 Accepted: 3 December 2021

Published online: 29 January 2022

\section{References}

1. Lozano R, Naghavi M, Foreman K, et al. Global and regional mortality from 235 causes of death for 20 age groups in 1990 and 2010: a systematic analfor the Global Burden of Disease Study 2010. Lancet. 2012;380(9859):2095-128.

2. Horby P. Improving preparedness for the next flu pandemic. Nat Microbiol. 2018;3(8):848-50.

3. Jain S, Kamimoto L, Bramley AM, et al. hospitalised patients with 2009 H1N1 influenza in the United States, April-June 2009. N Engl J Med. 2009;361(20):1935-44.

4. Dominguez-Cherit G, De la Torre A, Rishu A, Pinto R, Namendys-Silva SA, Camacho-Ortiz A, et al. Influenza A (H1N1pdm09)-related critical illness and mortality in Mexico and Canada, 2014. Crit Care Med. 2016:44(10):1861-70.

5. Meltzer MI, Patel A, Ajao A, et al. Estimates of the demand for mechanical ventilation in the United States during an influenza pandemic. Clin Infect Dis. 2015;60(Suppl 1):S52-7.

6. Oliveira EC, Marik PE, Colice G. Influenza pneumonia: a descriptive study. Chest. 2001;119(6):1717-23.

7. Roca O, Caralt B, Messika J, et al. An index combining respiratory rate and oxygenation to predict outcome of nasal high-flow therapy. Am J Respir Crit Care Med. 2019;199(11):1368-76.

8. Karim HMR, Esquinas AM. Success or failure of high-flow nasal oxygen therapy: the ROX index is good, but a modified ROX index may be better. Am J Respir Crit Care Med. 2019;200(1):116-7.

9. Duan J, Han X, Bai L, et al. Assessment of heart rate, acidosis, consciousness, oxygenation, and respiratory rate to predict noninvasive ventilation failure in hypoxemic patients. Intensive Care Med. 2017;43(2):192-9.

10. Chen L, Zhou F, Li H, et al. Disease characteristics and management of hospitalised adolescents and adults with community-acquired pneumonia in China: a retrospective multicentre survey. BMJ Open. 2018;8:e018709.

11. Collins JP, Campbell AP, Openo K, et al. Outcomes of immunocompromised adults hospitalized with laboratory-confirmed influenza in the United States, 2011-2015. Clin Infect Dis. 2020;70(10):2121-30.

12. Ferrer M, Esquinas A, Leon M, Gonzalez G, Alarcon A, Torres A. Noninvasive ventilation in severe hypoxemic respiratory failure: a randomized clinical trial. Am J Respir Crit Care Med. 2003;168:1438-44.

13. Katzen J, Kohn R, Houk JL, et al. Early oseltamivir after hospital admission is associated with shortened hospitalization: a 5-year analysis of oseltamivir timing and clinical outcomes. Clin Infect Dis. 2019;69(1):52-8.

14. Jain S, Self WH, Wunderink RG, et al. Community-acquired pneumonia requiring hospitalization among U.S. adults. N Engl J Med. 2015;373(5):415-27.

15. Zhang Z. Multiple imputation with multivariate imputation by chained equation (MICE) package. Ann Transl Med. 2016;4(2):30.

16. Cantan B, Luyt C-E, Martin-Loeches I. Influenza infections and emergent viral infections in intensive care unit. Semin Respir Crit Care Med. 2019:40(4):488-97.

17. Martín-Loeches I, Sanchez-Corral A, Diaz E, et al. Community-acquired respiratory coinfection in critically ill patients with pandemic 2009 influenza A(H1N1) virus. Chest. 2011;139(3):555-62.

18. Mertz D, Kim TH, Johnstone J, et al. Populations at risk for severe or complicated influenza illness: systematic review and meta-analysis. BMJ. 2013:347:f5061.

19. Chen X, Liu S, Goraya MU, et al. Host immune response to influenza A virus infection. Front Immunol. 2018:9:320.

20. Weiskopf D, Weinberger B, Grubeck-Loebenstein B. The aging of the immune system. Transpl Int. 2009;22(11):1041-50.

21. Shi SJ, Li H, Liu M, et al. Mortality prediction to hospitalized patients with influenza pneumonia: $\mathrm{PO}_{2} / \mathrm{FiO}_{2}$ combined lymphocyte count is the answer. Clin Respir J. 2017;11(3):352-60.

22. Bellelli V, d'Ettorre G, Celani $L$, et al. Clinical significance of lymphocytopenia in patients hospitalized with pneumonia caused by influenza virus. Crit Care. 2019;23(1):330.

23. Boonnak K, Vogel L, Feldmann F, et al. Lymphopenia associated with highly virulent $\mathrm{H} 5 \mathrm{~N} 1$ virus infection due to plasmacytoid dendritic cellmediated apoptosis of T cells. J Immunol. 2014;192(12):5906-12.

24. Smith PK, Wang SZ, Dowling KD, et al. Leucocyte populations in respiratory syncytial virus-induced bronchiolitis. J Paediatr Child Health. 2001:37(2):146-51. 
25. Zhou Y, Xiaofang Fu, Liu X, et al. Use of corticosteroids in influenzaassociated acute respiratory distress syndrome and severe pneumonia: a systemic review and meta-analysis. Sci Rep. 2020;10(1):3044.

26. Hui DS, Lee N, Chan PK, Beigel JH. The role of adjuvant immunomodulatory agents for treatment of severe influenza. Antiviral Res. 2018;150:202-16.

27. Herfst S, van den Brand JMA, Schrauwen EJA, et al. Pandemic 2009 H1N influenza virus causes diffuse alveolar damage in cynomolgus macaques. Vet Pathol. 2010;47(6):1040-7.

28. Kraut JA, Madias NE. Treatment of acute metabolic acidosis: a pathophysiologic approach. Nat Rev Nephrol. 2012;8(10):589-601.

29. Tobin MJ, Laghi F, Jubran A. Ventilatory failure, ventilator support, and ventilator weaning. Compr Physiol. 2012;2(4):2871-921.

30. Davidson S. Treating influenza infection, from now and into the future Front Immunol. 2018;9:1946

31. Chen L, Han X, Li YL, et al. The impact of early neuraminidase inhibitor therapy on clinical outcomes in patients hospitalised with influenza A-related pneumonia: a multicenter, retrospective study. BMC Infect Dis. 2020;20(1):628.

32. Muthuri SG, Venkatesan S, Myles PR, et al. Impact of neuraminidase inhibitors on influenza $\mathrm{A}(\mathrm{H} 1 \mathrm{~N} 1)$ pdm09-related pneumonia: an individual participant data meta-analysis. Influenza Other Respir Viruses. 2016;10(3):192-204

\section{Publisher's Note}

Springer Nature remains neutral with regard to jurisdictional claims in published maps and institutional affiliations.

- fast, convenient online submission

- thorough peer review by experienced researchers in your field

- rapid publication on acceptance

- support for research data, including large and complex data types

- gold Open Access which fosters wider collaboration and increased citations

- maximum visibility for your research: over $100 \mathrm{M}$ website views per year

At BMC, research is always in progress.

Learn more biomedcentral.com/submissions 